\title{
Segmentasi Konsumen Berdasarkan Model Recency, Frequency, Monetary dengan Metode K-Means
}

\section{Consumer Segmentation Based on Recency, Frequency, Monetary Models with the K-Means Method}

\author{
Atik Febriani ${ }^{1^{*}}$, Syahfara Ashari Putri ${ }^{1}$ \\ ${ }^{1}$ Program Studi Teknik Industri, Institut Teknologi Telkom Purwokerto, Jl. DI Panjaitan No.128, Purwokerto \\ Kidul, Banyumas 53147, Indonesia
}

Diterima: 4 Mei, 2020 / Disetujui: 24 Juli, 2020

\begin{abstract}
A good company is a company that is responsive to market changes and opportunities by utilizing existing data and information. Company data and information can come from internal or external sources. One of the internal data sources that can be utilized is customer data. This data will be used as the basis for determining customer segmentation. Segmentation is a process to determine customer characteristics with certain similarities, making it easier to extract information related to profitable customers. Customer business behavior can be seen from recency (last transaction period), frequency (number of transactions), and monetary (rupiah issued) or known as RFM analysis. The effective RFM analysis helps achieve the implementation of customer relationship management because this model is an important facility in measuring the profitability of customer value. To consider this RFM model, researchers use clustering which assumes that customers are in the same cluster, then consider customers with customers in the cluster. This clustering will display customer segmentation. This clustering method uses K-Means clustering. From the results of data processing, 3 clusters were formed from 25 customer data. Based on the clusters formed, it can be concluded that customer purchases have a different pattern. Clusters included in the segment of potential customers are cluster 1. Clusters are needed to get customers who previously had low $R$, high $F$, and high M values. While the strategy that needs to be improved is cluster 2 .
\end{abstract}

Keywords: Recency Frequency Monetary Model, K-Means clustering, Customer Relationship Management, Consumer segmentation

\begin{abstract}
ABSTRAK
Perusahaan yang baik adalah perusahaan yang responsif pada perubahan dan peluang pasar dengan cara memanfaatkan data dan informasi yang ada. Data dan informasi perusahaan bisa berasal dari sumber internal maupun ekternal. Salah satu sumber data internal yang dapat dimanfaatkan adalah data pelanggan. Data tersebut akan digunakan sebagai dasar dalam penentuan segmentasi pelanggan. Segmentasi merupakan proses untuk mengetahui karakteristik pelanggan dengan kesamaan tertentu, sehingga mempermudah penggalian informasi terkait pelanggan yang profitable. Perilaku bisnis pelanggan dapat dilihat dari recency (rentang waktu transaksi terakhir), frequency (jumlah transaksi), dan monetary (rupiah yang dikeluarkan) atau dikenal dengan analisis RFM. Analisis RFM secara efektif membantu tercapainya implementasi customer relationship management karena model ini merupakan salah satu sarana penting dalam mengukur profitabilitas nilai pelanggan. Untuk menguji model RFM ini, peneliti menggunakan klasterisasi yang menggunakan asumsi bahwa jika pelanggan berada pada klaster yang sama maka dianggap perilaku pelanggan sama dengan pelanggan yang ada di dalam klaster tersebut. Klasterisasi tersebut akan menunjukkan segmentasi pelanggan. Metode klasterisasi ini menggunakan K-Means clustering. Dari hasil pengolahan data, terbentuk 3 klaster yang terbentuk dari 25 data pelanggan. Berdasarkan klaster yang terbentuk, dapat disimpulkan bahwa bahwa perilaku pembelian pelanggan memiliki pola yang berbeda-beda. Klaster yang termasuk dalam segmen pelanggan potensial adalah klaster 1. Klaster tersebut perlu dipertahankan agar pelanggan tersebut tetap memiliki nilai $\mathrm{R}$ yang rendah, $\mathrm{F}$ yang tinggi dan $\mathrm{M}$ yang tinggi. Sementara itu, klaster yang perlu ditingkatkan lagi strateginya adalah kluster 2.
\end{abstract}

Kata Kunci: Model Recency Frequency Monetary, K-Means clustering, Customer Relationship Management, Segmentasi konsumen

*email: atik@ittelkom-pwt.ac.id 


\section{PENDAHULUAN}

Gaya hidup paraktis dan cepat telah menjadi ciri khas gaya hidup manusia modern. Salah satu contoh yang bisa dilihat adalah tentang cara orang mencuci pakaian. Kebutuhan mencuci pakaian merupakan salah satu kebutuhan utama dalam suatu keluarga. Cara mencuci pakaian mulai ditinggalkan karena adanya teknologi baru yaitu mesin cuci. Namun, mesin cuci belum pasti dimiliki oleh setiap individu atau setiap keluarga. Perubahan gaya hidup, tuntutan pekerjaan, kesibukan mahasiswa, dan kesibukkan rumah tangga menyebabkan waktu mencuci pakaian, menjemur pakaian, dan menyetrika pakaian hampir tidak ada. Alternatif lain untuk menyelesaikan masalah ini yaitu dengan memanfaatkan jasa laundry. Jasa laundry yaitu jasa mencuci dan menyetrika pakaian. Jumlah jasa laundry dari tahun ke tahun berbanding lurus dengan meningkatnya jumlah pelanggan yang ingin menggunakan jasa laundry. Setiap penyedia layanan seyogyanya menawarkan berbagai keunggulan kepada pelanggan agar perusahaan dapat terus bertahan dalam persaingan dengan perusahaan pesaing (Wilujeng et al., 2019).

Konsumen akan membeli suatu produk atau jasa sebagai solusi atas permasalahan yang dihadapinya. Tanpa adanya pengenalan masalah yang muncul, konsumen tidak dapat menentukan produk atau jasa yang akan dibeli. Kondisi ini diawali dari pengenalan kebutuhan konsumen itu sendiri. Pada kondisi ini, konsumen mengetahui produk atau jasa apa yang dibutuhkan (Hidayat, 2016). Problem recognition dimulai dari pengenalan kebutuhan (need recognition). Konsumen akan melihat dua kondisi yaitu kondisi ideal dan kondisi nyata. Konsumen akan memerhatikan adanya perbedaan atau gap antara kondisi nyata dengan kondisi yang diinginkannya. Pada tahap ini, muncul adanya rasa tidak puas akan kondisi sekarang. Ketika konsumen menyadari adanya masalah need recognition maka konsumen akan mencari kondisi ideal yang sesuai dengan harapan dan keinginannya (San dan Yazdanifard, 2014). Persepsi pelanggan yang terbentuk diharapkan bersifat positif agar dampak yang baik secara berkelanjutan dapat tercipta (Rembulan, 2018).

Penelitian terdahulu membahas tentang kinerja perusahaan dari sudut pandang karyawan
(Wilujeng, Suyoto dan Rembulan, 2019; Rowena, Wilujeng dan Rembulan, 2020). Pada penelitian ini kinerja perusahaan dipandang dari sudut pandang konsumen. Konsumen yang puas akan cenderung melakukan pembelian kembali terhadap produk yang ditawarkan. Penelitian sebelumnya menemukan bahwa konsumen menginginkan kualitas pelayanan yang lebih dibandingkan dengan kualitas pelayanan yang diterima saat ini (Wilujeng dan Rembulan, 2019).

Perusahaan yang baik adalah perusahaan yang responsif pada perubahan dan peluang pasar dengan cara memanfaatkan data dan informasi yang ada. Data dan informasi perusahaan bisa berasal dari sumber internal maupun ekternal. Salah satu sumber data internal yang dapat dimanfaatkan adalah data pelanggan.

Data pelanggan dapat dimanfaatkan untuk melakukan strategi pemasaran produk dan jasa dengan tepat ke tiap segmen pelanggan. Segmentasi pelanggan merupakan elemen yang digunakan untuk mengidentifikasi pelanggan dalam fase pertama CRM yaitu akuisisi pelanggan (Ngai, Xiu dan Chau, 2009). Akuisisi pelanggan tidak lagi berlaku jika pelanggan tersebut sudah melakukan pembelian produk/jasa sebelumnya, atau yang biasa disebut dengan retensi pelanggan. Retensi pelanggan merupakan strategi pasca penjualan yang dibutuhkan untuk menciptakan loyalitas dari hasil akusisi pelanggan baru tersebut. Loyalitas akan dicapai jika kebutuhan pelanggan terpenuhi. Penelitian sebelumnya membahas pemenuhan permintaan pelanggan dengan melakukan rekayasa pada jaringan distribusi (Rembulan et al., 2020).

Segmentasi pelanggan adalah praktik mempartisi pelanggan menjadi himpunan bagian yang homogen sehingga masing-masing subset dapat ditangani sebagai khalayak pemasaran yang unik (Buttle dan Maklan, 2015). Pengelompokan data adalah teknik eksplorasi sekaligus analisis deskriptif untuk mempelajari berbagai jenis kumpulan data, termasuk perilaku konsumen (Arunachalam dan Kumar, 2018). Perilaku konsumen tidak hanya didasarkan pada standar hidup pelanggan, namun juga berdasarkan preferensi membeli produk/jasa dan tren pembelian yang pernah dilakukan. Segmentasi pelanggan digunakan untuk mengukur nilai pelanggan (customer 
value) sehingga perusahaan bisa menentukan pelanggan yang memberikan keuntungan yang besar dan pelanggan yang tidak memberikan keuntungan. Hal ini dibedakan karena tidak semua pelanggan dilayani dan dipertahankan oleh perusahaan. Jika pelanggan tersebut tidak memberikan kontribusi berupa keuntungan kepada perusahaan maka perusahaan tidak perlu memberikan perhatian dan mengeluarkan biaya dalam mempertahankannya.

Customer value dikenal dengan nama Lifetime Value (LTV), Customer Lifetime Value (CLV), Customer Equity (CE) dan Customer Profitability (CP) (Kim et al., 2006). Analisis CLV ini berguna dalam memprediksi total pendapatan bersih perusahaan yang dapat diharapkan yang berasal dari pelanggan. Penelitian sebelumnya melakukan klasterisasi terhadap konsumen produk finansial di Kuwait (Al-Salem dan Mostafa, 2019). Penelitian sebelumnya membahas segmentasi pasar berdasarkan penggunaan, persepsi dan keyakinan (Arunachalam dan Kumar, 2018). Penelitian ini menggunakan model Recency, Frequency dan Monetary (RFM).

Model RFM ini diperkenalkan pertama kali oleh Arthur Huges dan telah banyak digunakan oleh industri manufaktur, peritel dan industri jasa. Model RFM secara efektif membantu tercapainya Customer Relationship Management (CRM) karena model ini merupakan salah satu sarana penting dalam mengukur profitabilitas nilai pelanggan ( $\mathrm{He}$ dan $\mathrm{Li}$, 2016). Perusahaan hendaknya dapat memahami hal yang diinginkan pelanggan terhadap jasa yang diberikan (Wilujeng, Rembulan dan Regina, 2019). Untuk menguji model RFM ini, peneliti menggunakan klasterisasi yang menggunakan asumsi bahwa jika pelanggan berada pada klaster yang sama maka dianggap perilaku pelanggan sama dengan pelanggan yang ada di dalam klaster tersebut. Klasterisasi tersebut akan menunjukkan segmentasi pelanggan. Klasterisasi pada penelitian ini menggunakan metode K-Means clustering yang membagi data menjadi beberapa segmen. Algoritma K-Means clustering telah banyak digunakan pada penelitian sebelumnya dalam melakukan segmentasi pelanggan (Panuš et al., 2016).

\section{METODOLOGI}

\subsection{Model RFM}

Data yang digunakan dalam penelitian ini adalah data historis transaksi yang ada pada Laundry XYZ. Data tersebut memuat jumlah kiloan baju, jumlah pengeluaran dan intensitas melakukan transaksi di Laundry XYZ.

Model RFM terdiri dari 3 variabel yaitu:

a. Recency $(\mathrm{R})$ yaitu tanggal terakhir transaksi yang dilakukan pelanggan pada perusahaan selama periode analisis.

b. Frequency $(\mathrm{F})$ adalah jumlah transaksi yang dilakukan oleh pelanggan pada perusahaan selama periode yang dianalisis.

c. Monetary (M) yaitu jumlah uang yang dikeluarkan pelanggan untuk perusahaan selama periode analisis.

Data Laundry XYZ berupa nilai transaksi, jumlah transaksi dan jumlah uang akan dikelompokkan berdasarkan model R, F dan M.

\subsection{Metode K-Means Clustering}

Metode K-Means adalah metode yang dikategorikan ke dalam metode klasterisasi partisi. Algoritma ini paling banyak digunakan dalam CRM dan pemasaran (Kandeil, Saad dan Youssef, 2014). Hal ini disebabkan karena algoritma ini memiliki kesederhanaan dan kemudahan dalam menggunakannya dan pengguna bisa menentukan sendiri jumlah klasternya. K-Means Clustering dimulai dengan memilih sejumlah nilai klaster awal sesuai dengan jumlah yang diinginkan dan kemudian objek digabungkan ke dalam klaster-klaster tersebut.

Mengelompokkan data dengan metode $K$ Means clustering dilakukan dengan algoritma sebagai berikut:

1. Menentukan jumlah kelompok yang akan dibentuk.

2. Mengalokasikan data ke dalam kelompok yang sudah terbentuk secara acak.

3. Menghitung pusat kelompok dari data yang ada di masing-masing kelompok. Lokasi centroid setiap kelompok diambil dari ratarata semua nilai data dari setiap fiturnya. Jika M menyatakan jumlah data dalam sebuah kelompok, $i$ menyatakan fitur ke- $i$ dalam sebuah kelompok, dan $p$ menyatakan dimensi data, maka persamaan untuk menghitung centroid fitur ke-i digunakan persamaan (1). 


$$
C^{1}=\frac{1}{M} \sum_{j=1}^{M} X_{j}
$$

Persamaan (1) dilakukan sebanyak $p$ dimensi dari $i=1$ sampai dengan $i=p$.

4. Mengalokasikan masing-masing data ke centroid terdekat. Salah satu yang dapat digunakan adalah teknik pengukuran jarak atau yang biasa disebut dengan Euclidean Distance, seperti ditunjukkan pada persamaan (2).

$$
d=\sqrt{\left(X_{1}-X_{2}\right)^{2}+\left(Y_{1}-Y_{2}\right)^{2}}
$$

Pada penelitian ini, akan digunakan SPSS sebagai alat bantu dalam penyelesaian $K$ Means.

\section{HASIL DAN PEMBAHASAN}

\subsection{Model RFM}

Data yang digunakan dalam penelitian ini adalah data transaksi selama enam bulan, dengan total transaksi sebanyak 464 dari 25 data member. Selanutnya akan dicari nilai minimal dan maksimal dari masing-masing variable $\mathrm{R}, \mathrm{F}$ dan M. Hasil Penilaian minimal dan maksimal dari data pelanggan berdasarkan model RFM.

Tabel 1. Penilaian Model RFM

\begin{tabular}{lrrr}
\hline Variabel & Minimal & Maksimal & Rata-rata \\
\hline Recency & 3 & 45 & 22.6 \\
Frequency & 5 & 27 & 18.56 \\
Monetary & 204,000 & 585,000 & 343,710 \\
\hline
\end{tabular}

Setelah hal tersebut di atas akan dilakukan penentuan jumlah klaster dalam penentuan segmen pelanggan dengan menggunakan SPSS. Dari data yang ada, akan dibentuk menjadi 3 klaster. Pengolahan data menggunakan $K$ Means clustering pada SPSS. Hasil yang diperoleh ditunjukkan pada Tabel 2.

Tabel 2. Initial Cluster Center

\begin{tabular}{lrrr}
\hline & \multicolumn{3}{c}{ Cluster } \\
\cline { 2 - 4 } & \multicolumn{1}{c}{$\mathbf{2}$} & \multicolumn{1}{c}{$\mathbf{3}$} \\
\hline Recency & 9 & 15 & 44 \\
Frequency & 20 & 17 & 26 \\
Monetary & 360,000 & 204,000 & 585,000 \\
\hline
\end{tabular}

Berdasarkan pengolahan data tersebut, diketahui anggota klaster 1 berjumlah 13 pelanggan, anggota klaster 2 berjumlah 10 pelanggan dan anggota klaster 3 berjumlah 2 pelanggan. Karakteristik dari masing-masing klaster ditunjukkan pada Tabel 3.

Tabel 3. Karakteristik RFM

\begin{tabular}{cc}
\hline Klaster & Karakteristik RFM \\
\hline $\mathbf{1}$ & $\mathrm{R} \downarrow \mathrm{F} \uparrow \mathrm{M} \uparrow$ \\
$\mathbf{2}$ & $\mathrm{R} \downarrow \mathrm{F} \downarrow \mathrm{M} \downarrow$ \\
$\mathbf{3}$ & $\mathrm{R} \uparrow \mathrm{F} \downarrow \mathrm{M} \uparrow$ \\
\hline
\end{tabular}

Dari hasil tersebut dapat disimpulkan bahwa:

1. Segmen 1 yaitu recency $(\mathrm{R})$ rendah artinya bahwa pelanggan pada segmen ini baru-baru ini melakukan transaksi, frequency $(\mathrm{F})$ tinggi artinya ini merupakan pelanggan yang tergolong sering melakukan transaksi serta monetary (M) tinggi yang artinya jumlah uang yang dibelanjakan rata-rata tinggi.

2. Segmen 2 yaitu recency (R) yang rendah artinya baru-baru ini melakukan transaksi, frequency $(\mathrm{F})$ rendah artinya ini merupakan pelanggan yang jarang melakukan transaksi dan monetary (M) rendah yang artinya jumlah uang yang dibelanjakan relatif kecil.

3. Segmen 3 yaitu pelanggan yang memiliki recency ( $\mathrm{R})$ yang tinggi artinya bahwa pelanggan pada segmen ini sudah lama tidak melakukan transaksi, frequency (F) tinggi yang artinya sering melakukan transaksi dan monetary (M) tinggi artinya bahwa segmen ini merupakan segmen yang jumlah transaksinya tinggi.

\section{SIMPULAN}

Penelitian ini menghasilkan 3 klaster yang terbentuk dengan menggunakan metode $K$ means clustering dengan menggunakan SPSS. Berdasarkan klaster yang terbentuk, dapat disimpulkan bahwa bahwa perilaku pembelian pelanggan memiliki pola yang berbeda-beda. Klaster yang termasuk dalam segmen pelanggan potensial adalah klaster 1. Klaster tersebut perlu dipertahankan agar pelanggan tersebut tetap memiliki nilai $\mathrm{R}$ yang rendah, $\mathrm{F}$ yang tinggi dan $M$ yang tinggi. Sementara itu, klaster yang perlu ditingkatkan lagi strateginya adalah klaster 2 . Perlu dilakukan kajian lebih mendalam terkait peta demografis dan profil pelanggan untuk dapat menentukan strategi yang lebih tepat.

Penelitian selanjutnya dapat menggunakan metode klasterisasi yang lain karena setiap metode klasterisasi memiliki 
perbedaan performa (Arunachalam dan Kumar, 2018). Hasil metode klasterisasi yang baik akan mampu memberikan pengetahuan bagi perusahaan dalam memberikan perlakuan terhadap konsumen tertentu.

\section{DAFTAR PUSTAKA}

Al-Salem, F. dan Mostafa, M. M. (2019) "Clustering Kuwaiti Consumer Attitudes Towards Sharia-compliant Financial Products: A Self-organizing Maps Analysis," International Journal of Bank Marketing, 37(1), hal. 142-155. doi: 10.1108/IJBM-09-2017-0198.

Arunachalam, D. dan Kumar, N. (2018) "Benefit-based Consumer Segmentation and Performance Evaluation of Clustering Approaches: An Evidence of Data-driven Decision-making," Expert Systems with Applications. Elsevier Ltd, 111, hal. 1134. doi: 10.1016/j.eswa.2018.03.007.

Buttle, F. dan Maklan, S. (2015) Customer Relationship Management Concept and Technologies. 3 ed. New York: Routledge.

He, X. dan Li, C. (2016) "The Research and Application of Customer Segmentation on E-commerce Websites," in International Conference on Digital Home. doi: 10.1109/ICDH.2016.050.

Hidayat, R. (2016) "Faktor-faktor yang Mempengaruhi Consumer Decision Making Process (Studi Kasus Rumah Makan Bebek Sinjay Madura)," Journal of Industrial Engineering and Management Systems, 9(2), hal. 77-95.

Kandeil, D., Saad, A. dan Youssef, S. M. (2014) "A Two-phase Clustering Analysis for B2B Customer Segmentation," in Proceedings International Conference on Intelligent Networking and Collaborative Systems, hal. 221-228. doi: 10.1109/INCoS.2014.49.

Kim, S.-Y. et al. (2006) "Customer Segmentation and Strategy Development Based on Customer Lifetime Value: A Case Study," Expert SYstems with Applicatons, 31, hal. 101-107. doi: 10.1016/j.eswa.2005.09.004.

Ngai, E. W. T., Xiu, L. dan Chau, D. C. K. (2009) "Application of Data Mining Techniques in Customer Relationship Management: A Literature Review and Classification," Expert Systems with
Applications, 36, hal. 2592-2602. doi: 10.1016/j.eswa.2008.02.021.

Panuš, J. et al. (2016) "Customer Segmentation Utilization for Differentiated Approach," in The International Conference on Information and Digital Technologies, hal. 227-233. doi: 10.1109/DT.2016.7557178.

Rembulan, G. D. (2018) "Faktor-faktor yang Memengaruhi Getok Tular pada Usaha Restoran Waralaba di Jakarta," Jurnal Pengabdian dan Kewirausahaan, 2(1), hal. 17-28.

Rembulan, G. D. et al. (2020) "Optimalisasi Panjang Jaringan Pipa Air Bersih di DKI Jakarta Menggunakan Minimum Spanning Tree," Jurnal Intech, 6(1), hal. 75-87. doi: 10.30656/intech.v6i1.2164.

Rowena, J., Wilujeng, F. R. dan Rembulan, G. D. (2020) "Pengaruh Kualitas Layanan dalam Menciptakan Kepuasan Publik di Kantor Pelayanan Publik, Jakarta Utara," Journal of Industrial Engineering and Management Systems, 13(1), hal. 27-34. doi: 10.30813/jiems.v13i1.2083.

San, Y. W. dan Yazdanifard, R. (2014) "How Consumer Decision Making Process Differ from Youngster to Older Consumer Generation," Journal of Research in Marketing, 2(2), hal. 151156.

Wilujeng, F. R. et al. (2019) "Meningkatkan Kepuasan Pelanggan pada Dua Bisnis ECommerce Terbesar di Indonesia dengan Menggunakan Analisis Servqual dan IPA," in Prosiding Seminar Nasional Sains dan Teknologi. Jakarta: Fakultas Teknik Universitas Muhammadiyah Jakarta, hal. 1-9.

Wilujeng, F. R. dan Rembulan, G. D. (2019) "Perancangan Model Kualitas Pelayanan Puskesmas dengan Metode Importance Performance Analysis (IPA) dan Quality Function Deployment (QFD)," Jurnal Intech, 5(2), hal. 43-50. doi: 10.30656/intech.v5i2.1675.

Wilujeng, F. R., Rembulan, G. D. dan Regina, T. (2019) "Pengukuran Kualitas Layanan dengan Metode Service Quality pada Puskesmas Jakarta Utara," in Prosiding Seminar Nasional Teknik Industri. Lhokseumawe: Universitas Malikussaleh. Wilujeng, F. R., Suyoto, Y. T. dan Rembulan, G. D. (2019) "Dampak Faktor Motivasi 
terhadap Performa Kerja Layanan E-ISSN 2579-8154

Publik," in Prosiding Seminar Nasional

Universitas Malikussaleh, hal. 2-7.

Teknik Industri. Lhokseumawe: 